\title{
The Role of Entrepreneurship in Economic Development
}

\author{
Aakash Ranjan \\ Muskurahat Foundation, Mumbai, India \\ Email address: \\ aakashr26@yahoo.com \\ To cite this article: \\ Aakash Ranjan. The Role of Entrepreneurship in Economic Development. American Journal of Management Science and Engineering. \\ Vol. 4, No. 6, 2019, pp. 87-90. doi: 10.11648/j.ajmse.20190406.11
}

Received: August 9, 2019; Accepted: October 18, 2019; Published: December 4, 2019

\begin{abstract}
Entrepreneurship is one of the most Important Inputs in the Economic Development of a country. According to Harbison, entrepreneurs are prime movers of innovation. Entrepreneurship is known for the high risks involved in launching a startup. The fact is people often suffer failures along the path to success, and some businesses have to close, due to a lack of fund, sales decisions, or a lack of demand in the market. That's why entrepreneurship is mostly viewed as something risky and out of the comfort zone. Enterprise takes courage to make one's dreams come true and see possibilities, solutions and opportunities for the future where others see only problems. Entrepreneurship is all about putting to better use the resources which are considered to be of low value with an aim of earning income. Economic growth is measured in terms of a sustained increase in real income. It is the entrepreneurial communities who complement and supplement the economic growth increase per capita income by identifying and establishing profitable business ventures. Entrepreneurs supplement the economic growth by enhancing the physical quality of life. Establishment of enterprises leads to increase in employment avenues both directly and indirectly. Consequently, poverty is alleviated as per capita income grows. This results in improving the physical quality of life which is an indicator of economic growth. Entrepreneurs help in the growth of infrastructural facilities such as roads, bridges, buildings, factories, etc. which are the cornerstones of economic growth. Establishment of factories and industries in a particular locality presupposes the growth of infrastructural facilities.
\end{abstract}

Keywords: Entrepreneurship, Economic Growth, Positive and Negative Impact

\section{Introduction}

The word entrepreneurship means has its origin in French Language which refers to organizers of musical or other entertainment. An entrepreneur is a person who has already started or is in the process of starting an enterprise. Entrepreneurship play vital role in the Economic growth and Development of the country and new product formation and technological change in production process and economic transformation is occurs due to effective Entrepreneurship. The Entrepreneurs with their ability to scan, analyze and identify opportunities in the environment transform them into business proposition through creation of economic entities. One of the most important goals of contemporary economics is determining the factors that cause economic growth. Traditional neoclassical theory holds that the economic growth of a country is determined by the supplies of both labor and capital the country possesses and level of technology present in that country. The level of technology in a given society is heavily dependent on the level of knowledge in that society. An entrepreneur is a person who starts an enterprise. He searches for change and responds to it. Entrepreneurship involves a fusion of capital, technology and human talent. Entrepreneurship is equally applicable to big and small businesses, to economic and non-economic activities. Different entrepreneurs might have some common traits but all of them will have some different and unique features. This paper will Provide evidence that entrepreneurship should be included as an important cause of economic growth independent of the other factors. We will begin with a review of relevant literature, and then move to an overview of the data and variables used along with a description of the statistical methodology. $[6,1,2]$

\section{Literature Review}

Concept of entrepreneurship as an organized knowledge came into being about hundred years ago. Though, the economists from Adam Smith to Marshall were talking about 
it, but without assigning the name of entrepreneurship. They used the terms as employer, the master, the merchant and the undertaker for carrying out different entrepreneurial activities now comprising of entrepreneurship. It was Eantillon, who first brought out the term entrepreneur and entrepreneurship was recognized in economic literature.

The traditional neoclassical theory of economic growth was first developed by Robert Solow in his 1956 paper "A Contribution to the Theory of Economic Growth". In this paper, Solow argues that economic growth is a function of two inputs- the levels of capital and labor in a given area. The exact nature of this function is determined by the technological possibilities available to the society in question. Thus, under this theory, the economic growth of a given country is determined by the amounts of labor and capital that country possesses and the technological possibilities to which that country has access (i.e., the level of knowledge within that country). The entrepreneur organizes and operates an enterprise for personal gain. $\mathrm{He}$ pays current prices for the materials consumed in the business, for the use of the land, for the personal services he employs, and for the capital he requires. He contributes his own initiative, skill, and ingenuity in planning, organizing, and administering the enterprise. He also assumes the chance of loss and gain consequent to unforeseen and uncontrollable circumstances. The net residue of the annual receipts of the enterprise after all costs have been paid, he retains for himself. [3, 9, 10]

\section{Definitions of Entrepreneurship}

\subsection{Alex Kirshbaum, President of NUE Agency, a Talent Agency Focused on Concerts, Tours and Endorsement Deals Globally}

"No matter how much money you make or how many things you have or if your business is worth millions or trillions - if you wake up in the morning and are happy with the person you are, if you believe you're wellrounded by doing well (and your doing well by doing social good), then that defines success as an entrepreneur. The money will come. I will never let a number define who I am as an entrepreneur. Believing that success is based on a monetary figure is a small way of describing a big picture. Do well while doing good, and you can change the world while being a great entrepreneur. Don't let some stat or ego-play dictate what you believe an entrepreneur is or is not."

\subsection{Matt Van Horn, Vice President of Business for Path}

"I try not to define my success based on the amount I earn or anything like that. The coolness factor of the work I do matters a whole lot more. Entrepreneurs work longer and harder than anyone else, so you absolutely have to think what you're doing every day is cool. Otherwise, what are you doing it for?

\subsection{Jordan Edelson, CEO of Appetizer Mobile LLC, a Mobile Development Application Platform and Consulting Company}

"For me, defining my success has been about what I have been able to create out of nothing and how far I have come. Each year, I look back and assess what I have been able to accomplish in the previous year. I continually set goals for my business and celebrate each milestone as a sign of where the business is going. It's tempting to just define success by the revenue you are bringing in, but I would advise entrepreneurs in the startup phase not to make that your only barometer for success. Of course, increasing revenue is a great sign of success, but also make sure to take pride in the fact that you are succeeding in doing something you love and that brings value to others."

\subsection{Marni Galison, Founder and CEO of Sunday at Noon, a Personalized Matchmaking and Event Company in Manhattan, New York}

"I won't lie, revenue isn't bad, but I could make money in a lot of different fields by working for other people. For me, it's the freedom to make enough money for a good life and the freedom to make a schedule that lets me be a good mom!" $[8,15]$

\section{Methodology}

The study is exploratory by nature, where attempt has been made to explore the positive and negative impact of entrepreneurship in the economic development. [7, 5]

\section{Positive Impact of Entrepreneurship in Economic Development}

Following are the positive impact of entrepreneurship in the economic development:

\subsection{Investing in Products and Services People Need}

What motivates a person to start a new business? According to traditional models, entrepreneurs create new businesses in response to unmet needs and demands in the market. That is, there is an opportunity to provide a product or service that is not currently in existence, or otherwise available. Economists refer to these business-starters as "opportunity" entrepreneurs in order to distinguish these individuals from those who start businesses for lack of better work opportunities. So-called "opportunity" entrepreneurs, who launch new enterprises in response to market needs, are key players when it comes to fostering economic growth in a region. They enable access to goods and services that populations require in order to be productive. This is not to ignore "necessity" entrepreneurs that launch enterprises because they have no other options. Both can and do contribute to economic growth 


\subsection{Providing Employment Opportunities}

New businesses need to hire employees. They create jobs and these economic opportunities uplift and support communities through increasing the quality of life and overall standard of living.

\subsection{Commerce and Regional Economic Integration}

Technology has made it possible for small, entrepreneurled businesses to expand into regional and global markets. When new businesses export goods and services to nearby regions, these enterprises contribute directly to a region's productivity and earnings. This increase in revenue strengthens an economy and promotes the overall welfare of a population. Economies that trade with one another are almost always better off. Politics aside, engaging in regional and international trade promotes investment in regional transportation and infrastructure, which also strengthens economies. This has never been more true than it is today, as we live in an increasingly interconnected global economy. Even for a large and advanced economy like the United States, foreign markets have a significant role. Foreign trade, according to some estimates, is responsible for over 90 percent of our economic growth.

What exactly is innovation and how does it promote economic development? Under what conditions, do entrepreneurs innovate? A widely-accepted definition measures innovation using a set of criteria including how many new products are invented, the percentage of high-tech jobs, and the size of the talent pool available to tech industry employers. More recently and increasingly, our definition of innovation has expanded to include the development of new service offerings, business models, pricing plans, and routes to market. While the role that startups and young tech companies play in job creation is well documented, their contribution to overall productivity is less intuitive and not discussed as often. To better understand how innovation contributes to economic development.

\subsection{New Technologies Promote Efficiency}

The ability to turn ideas into new products and services that people need is the fount of prosperity for any developed country. Economic growth, generally speaking, is driven by new technologies and their creative applications. Periods of rapid innovation historically have been accompanied by periods of strong economic growth. The impetus of innovation is the greatest natural resource of all: the human mind. Creating innovative products and solutions requires an educated population and an environment where collaborative work can take place. In addition to being good for business, education increases workforce creativity and quality of life.

\subsection{Addressing Environmental Challenges}

Innovation is (and will continue to be) crucial when it comes to addressing the enormous environmental challenges we face today: combating climate change, lowering global greenhouse gas emissions, and preserving biodiversity in the environment. Without power for extended periods of time, commerce comes to a halt. Without water, we cannot live. Reliable access to these innovations (such as irrigation technology, electricity, and urban infrastructure) increases productivity and enhances economic development.

\subsection{Innovation Impacts Socio-economic Objectives}

Innovative business practices create efficiency and conserve resources. Innovation in agriculture is especially relevant for addressing socioeconomic challenges (in addition to encouraging economic growth). In the U.S., for instance, People's waste billions of dollars annually due to inefficiencies and uncompetitive practices in healthcare system. Hopefully, new ideas and innovations in the future will address these problems, resulting in further reforms. When this occurs, Americans' overall health and quality of life will benefit, and so will economy if there wasteful healthcare costs also decrease.

\subsection{Innovation Happens Where There Is Competition}

In essence, there is a positive feedback loop among innovation, entrepreneurship, and economic development.

New and growing businesses represent the principal sources of job creation and innovative activity in an economy, two factors that generally result in the rising standards of living for all.

However, it's important to understand that entrepreneurship and innovation are dependent on access and participation. For entrepreneurs to bring new ideas to life, they need access to education and a level-playing field on which to compete. In this vein, the role of government leaders and public policy is to create conditions that allow more entrepreneurs to start businesses by implementing policies which nurture that environment so those businesses can grow. Economic growth suffers when entrepreneurial activity is unevenly spread socioeconomically, demographically, and geographically. Under the right conditions, entrepreneurs have an incredible power: they help regional areas prosper economically, and they also serve society as they help engineer innovative solutions to problems and challenges. $[11,13]$

\section{Negative Impact of Entrepreneurship in Economic Development}

\subsection{Low Quality Entrepreneurs}

The ability of entrepreneur is difficult to observe ex ante and as such measures to facilitate the entry of entrepreneurs may also encourage entrepreneurs of low ability.

De Meza and Webb (1987; extended in 1999) show that credit market imperfects may lead to "overinvestment", and not underinvestment as in the Stiglitz and Weiss (1981) model, when ability (and profits) differs amongst entrepreneurs, and accurately judge ability. In essence high profit (ability) entrepreneurs subsidize low profit (ability) 
entrepreneurs. They argue that a tax on interest rates in such a case could improve social welfare. builds on De Meza and Webb and shows that their conclusions are only likely to hold under special conditions. point out that entrepreneurial ability affects the success of a firm, which in turn matters for the probability of the entrepreneur repaying a loan. Because banks cannot observe any entrepreneur's ability ex ante, interest rates on start-up capital will reflect average entrepreneurial ability. If the proportion of entrepreneurs of low ability increases, it will result in higher borrowing costs, which impose a negative externality on entrepreneurs of high ability, who will consequently borrow and invest less.

A second channel through which the entry of entrepreneurs with low ability might hinder economic development is through the impact of entrepreneurial ability on the productivity of employed workers. Entrepreneurs of low ability will have less productive workers, who will earn lower wages. By reducing wage costs, these entrepreneurs in effect lower the opportunity costs of entrepreneurship or selfemployment, and facilitate the entry of more low-ability entrepreneurs.

\subsection{Loss of Confidence and Direction}

Europe has lost confidence and direction in its innovation efforts. European policy makers know too little about vertical industries and make generic appeals to our innovation culture without using their power to shape innovation culture in verticals. There is no real target other than the most general ones: for example to be the most innovative region, to lead in the knowledge society. These cannot act as calls to action. The United States assumes its inheritance of an innovative culture will see it adapt to the current structural changes in the world economy. It won't without policy makers setting a clearer direction.

\subsection{The Negative Equity Culture}

Companies are currently being asked to innovate in noninnovative cultures, in industries where there is negative equity in innovation culture. That is why they are finding it difficult. To innovate in some areas of fast moving consumer goods is almost a betrayal of ethics, for example in food additives. This is what negative equity means. You can innovate but the conditions are essentially negative. Perhaps more controversially than food, mobility is in danger of becoming a negative innovation culture. We see innovation in areas like location-based services but the reality is it is difficult to envisage how location-based services add to the wealth creating capacity of humans. In that sense the ITC revolution is played out; what's left is how to share out the spoils from a maturing industry. On the face of it you can argue that mobile has twenty years to play out. But the nature of a maturing industry is its profitability and cash generation capability. The positive equity phase now belongs to embedded applications and machine to machine commerce. $[12,14]$

\section{Conclusion}

The entrepreneurship have positive impact on economic development as it gear up capital formation, generate huge employment, improve standard of living of the people of the nation, boost up wealth creation and decentralized distribution of economic resources, increases Gross National Product (GNP) and per capita income, promotes country's export trade and facilitates overall development of the nation.

Entrepreneurship will have negative/adverse impact on economic development in 2 conditions: (a) perverse allocation towards activities that are personally profitable but socially destructive or unproductive; and (b) low quality entrepreneurship that may have negative externalities. $[14,4]$

\section{References}

[1] Sorin-George Tomaa, Ana-Maria Grigorea, Paul Marinescua. Faculty of Administration and Business, University of Bucharest, 4-12 Regina Elisabeta, Bucharest, Romania.

[2] Schumpeter, J. A. The Theory of Economic Development. Cambridge, MA: Cambridge University Press.

[3] Jainendra Kumar Verma, Rajiv Gandhi National Fellow at Dept. of Applied Economics, University of Lucknow.

[4] Chandler, Entrepreneurship and Economic Growth. Cambridge, Harvard University Press.

[5] Hatten S Timothy. Small Business Entrepreneurship and Beyond. Prentice Hall, New Jersey.

[6] Chandan Kumar, Senior Branch Manager, Central Bank of India.

[7] Peter Drucker, Innovation and Entrepreneurship, $\mathrm{http}: / / w w w . b u t l e r-b o w d o n . c o m / p e t e r-d r u c k e r---i n n o v a t i o n-$ and-entrepreneurship.html

[8] Carree, M., and R. Thurik. "The lag structure of the impact of business ownership on economic performance in OECD countries." Small Business Economics.

[9] Sternberg and S. Wennekers. "The Determinants and Effects of Using New Business Creation".

[10] Cooper, "Entrepreneurship: The Past, The Present, The Future." In Handbook of Entrepreneurship Research, 21-36.

[11] Rose Conry, udemy.com blog Article. https://blog.udemy.com/importance-of-entrepreneurship/

[12] Wim Naudé, United Nation University, Blog. https://unu.edu/publications/articles/are-entrepreneurialsocieties-also-happier.html

[13] Chinmoy Kumar, PreserveArticles.com blog. http://www.preservearticles.com/business/role-of-anentrepreneur-in-economic-development/1770

[14] Shawn. Grimsley, study.com website. https://study.com/academy/lesson/what-is-an-entrepreneurdefinition-characteristics-examples.html

[15] DK Sinha, Your Article Library, the Next generation library Article. (1) http://www.yourarticlelibrary.com/essay/role-ofentrepreneurship-in-economic-development/40658 